\title{
SISTEMAS DE PRODUÇÃO DE BOVINOS E A EMISSÃO DE METANO
}

\author{
Keny Samejima Mascarenhas Lopes ${ }^{1}$
}

\author{
Kazuo Leonardo Almeida Yokobatake ${ }^{2}$
}

Rafael Silvio Bonilha Pinheiro ${ }^{3}$

RESUMO: O aumento da produção de alimentos é indispensável para suprir o crescimento da população mundial, porém, quantidade significativa da emissão de gás metano na atmosfera é provinda da agropecuária, auxiliando para mudanças climáticas. Para isto medidas de preservação do meio ambiente são cada vez mais estudada. Portanto, este trabalho teve como objetivo realizar uma revisão de literatura sobre os sistemas de produção de bovinos de corte e a relação da emissão de gás metano na atmosfera. Sabe-se que o manejo inadequado dos sistemas de produção animal, causa um aumento na emissão de metano por ruminantes. Atualmente, há sistemas de produção capazes de diminuir esta emissão principalmente, o sistema de plantio direto, integração lavoura-pecuária, integração lavoura-pecuária-floresta, dietas a base de alto concentrado, pastagens melhoradas e recuperação de áreas degradadas. No entanto os

\footnotetext{
${ }^{1}$ Zootecnista, Faculdade de Engenharia/Unesp Campus Ilha Solteira, Mestrando. E-mail. keny.samejima@gmail.com

${ }^{2}$ Zootecnista, Faculdade de Engenharia/Unesp Campus Ilha Solteira, Mestrando. E-mail. kazuo.yokobatake@gmail.com

${ }^{3}$ Zootecnista, Faculdade de Engenharia/Unesp Campus Ilha Solteira, Docente do Departamento de Biologia e Zootecnia. E-mail:rafaelsbp@bio.feis.unesp.br
} 
sistemas de produção mais intensivos são os que produzem menor emissão de gás metano, quando é considerado o tempo de abate (animais jovens).

Palavras-chave: Fermentação. Produção de gás. Ruminantes.

\section{INTRODUÇÃO}

A produção de carne bovina brasileira é principalmente de sistemas de produção em pastagem, sendo que o Brasil possui uma área de 180 milhões de hectares de pasto, onde mais da metade deste total apresentam algum grau de degradação do solo e da pastagem, principalmente em estágios avançados (EMBRAPA, 2012). Apesar da produção em pastagens deficientes no $4^{\circ}$ trimestre de 2012, o Brasil abateu 8,168 milhões de cabeças de bovinos, superando recorde de 1997 (IBGE, 2013). Segundo Lima (2002) a pecuária brasileira contribuía com 96\% da emissão de metano considerando todas as atividades agrícolas, sendo sua maior parte originária de sistemas extensivos.

A OECD (1991) considera o metano o gás gerado pelo processo de decomposição anaeróbica ou por combustão incompleta nas mudanças no uso do solo e áreas naturais pantanosas, nas criações de animais ruminantes e utilização como fonte de energia. Assim, com o aumento da escala de produção de alimentos no mundo, a emissão de gases na atmosfera também será maior. Na cadeia produtiva de alimentos de origem animal, tornaram-se alvo os animais ruminantes por liberarem na atmosfera o gás metano, gerado pelo processo de digestão através da fermentação de alimento no rúmen. Neste, os carboidratos são convertidos em ácidos graxos de cadeia curta liberando em algumas destas conversões o gás metano. A emissão de metano por animais ruminantes segundo a USEPA (2000) é responsável por 22\% deste gás na atmosfera, constituindo a terceira maior fonte em escala global. Cotton e Pielke (1995) afirmam que o gás metano possui uma participação no aquecimento global de 15\%.

Apesar da alta produção de carne bovina, a pecuária brasileira ainda não tem seu potencial produtivo aproveitado ao máximo, tendo como um dos maiores entraves a falta de planejamento por parte dos produtores rurais para suportar o período seco do ano e também a falta de assistência técnica. Tal período do ano, as pastagens encontram-se com baixo potencial produtivo, apresentando maiores porcentagens de colmos e menores 
porcentagens de lâminas foliares verdes, tendo conseqüentemente a diminuição dos valores de proteína bruta (PB), fibra insolúvel em detergente neutro (FDN) e matéria seca (MS) potencialmente digestível conforme o diferimento da pastagem, assim como maiores teores de FDN e FDN indigestível (SANTOS et al., 2009). Os autores supracitados, afirmam que o baixo valor nutricional de gramíneas em pastagens diferidas diminui o desempenho de bovinos mesmo quando suplementados com concentrado. Figueiredo et al. (2007) afirma que a maior precocidade dos sistemas de produção de carne é alcançada se houver ajuste nutricional entre a oferta de forragem e a curva crescente de demanda de nutrientes pelo animal, sendo a suplementação um incremento a eficiência de utilização da forragem em seus picos produtivos. Além dos prejuízos causados ao desempenho dos animais em períodos de seca do ano, há o aumento da emissão de metano no meio devido ao alimento ser pobre em energia e proteína, porém rico em fibra.

Diante do descrito este trabalho teve como objetivo realizar uma revisão de literatura com os principais sistemas de produção de bovinos de corte, seus manejos nutricionais e conseqüente emissão de gás metano.

\section{DESENVOLVIMENTO}

\subsection{Produção de metano entérico}

Ruminantes são animais distintos por conter um estômago com 4 câmaras, capacidade de ruminar e habilidade de processar materiais fibrosos em açucares digestivos. O rúmen é a câmara fermentativa primária de alimentos ingeridos, através de microrganismos que colonizam esse ambiente, com ausência de oxigênio e $\mathrm{pH}$ variando entre 6,5 e 6,8 (ASCHENBACH et al., 2012). A microflora ruminal é composta de bactérias, protozoários e fungos em ambiente anaeróbico. Os microrganismos são obrigatoriamente anaeróbios ou facultativos, capazes de decompor materiais complexos de plantas como a celulose, hemicelulose e amido em açucares simples para posterior fermentação e obtenção de ácidos orgânicos, hidrogênio, dióxido de carbono e metano (SALEEM, 2013).

A produção de metano no rúmen é resultado de uma série de processos bioquímicos na redução do dióxido de carbono com hidrogênio, utilização de acetato e 
outros compostos de grupo metil para a obtenção de energia e assim promover o crescimento de bactérias metanogênicas (PATRA, 2012). Além disso, as bactérias metanogênicas podem ter uma relação simbiótica com protozoários para aumentar seu acesso ao hidrogênio (FINLAY E FENCHEL, 1989). O pH ótimo para a produção de metano é de 6,0 a 6,5, que corresponde bem ao $\mathrm{pH}$ natural do rúmen, próximo a neutralidade, essa produção pode ser diminuída pela alteração do pH ruminal de acordo com o substrato oferecido ao animal, pois modifica a comunidade de microrganismos colonizadores do rúmen (POULSEN, 2012).

Para bovinos em pastagem, o rúmen encontra-se em seu pH natural, já para animais confinados e alimentados com dietas de alta energia, há a diminuição do pH devido à rápida fermentação no rúmen pelas bactérias (PLAIZIER et al., 2008; LECHARTIER e PEYRAUD, 2010). Esta rápida degradação do alimento e baixo pH, elimina em quase sua totalidade a população de protozoários e a extinção de fungos ruminais, por outro lado, a atividade de bactérias amilolíticas, produtoras e consumidoras de lactato é evidenciado (MACKIE e GILCHRIST, 1979). A ação fermentativa de microrganismos amilolíticos proporciona uma maior produção de propionato e diminui a formação de metano no rúmen (BANNINK et al., 2008).

\subsection{Sistema em pasto}

Figueiredo et al. (2007) avaliaram estratégias de suplementação baseada na idade de abate de animais em pasto, sendo elas 18, 24, 30 e 40 meses. Observaram que estratégias de suplementação para abate de animais com 40 meses de idade conferem o menor ganho de peso, comprometendo o ciclo produtivo, tal fato é devido à escassez de alimento no período seco do ano, provando que a perda de peso e ganhos não suficiente para garantir um crescimento contínuo e ascendente no período das águas. Ainda afirmam que animais produzidos exclusivamente em pastagens não satisfazem a demanda em nutrientes para manter seu crescimento na maioria das pastagens brasileiras. Na suplementação para animais abatidos com 18 meses de idade observaram-se maiores ganhos de peso, peso ao abate e maior produção de carne por hectare. Assim, os autores supracitados concluíram que a suplementação estratégica para bovinos é uma alternativa economicamente viável para sistemas de recria e 
terminação, sendo a de menor custo para o abate aos 18 meses e a pior para o abate aos 40 meses, este economicamente insustentável por não compensarem os custos operacionais efetivos.

Segundo Cabralet al. (2008), utilizando 32 bovinos em pastagem de Panicum maximum cv. Tanzânia em período das águas com suplementação mineral ou suplementação com concentrado nas proporções de 0,$2 ; 0,4$ e $0,6 \%$ do peso vivo observaram que a suplementação para bovinos não apresentou diferença significativa para peso final, ganho de peso total, ganho médio de peso, peso em jejum, custo, receita e margem bruta, pois a qualidade e quantidade de massa verde presentes nos pastos na época das águas é necessário para o bom desempenho dos animais. Assim a suplementação de bovinos na época das chuvas, não afeta o desempenho dos animais, mesmo causando o efeito substitutivo do pasto pela suplementação concentrada.

Cardoso (2012) comparando a emissão de gases em diferentes cenários de sistemas de produção brasileira, afirma que em sistemas com pastagens degradadas a produção de metano foi de $25.227 \mathrm{~kg}$. Nos sistemas intensivos (pastagem e confinamento) a produção foi de $16.685 \mathrm{~kg}$ de gás metano, sendo menor que o sistema de pastagens com presença de degradação. O mesmo autor ainda afirma que os sistemas em pasto produzem mais metano devido à maior permanência destes animais até $o$ abate que os confinados.

Para Beleosoff (2013) o uso de forragens com práticas de manejo eficientes, evitando acúmulo de material fibroso, pode diminuir a emissão de metano, bem como quando há pastejo simultâneo entre bovinos e ovinos. Segundo Beauchemin et al. (2008), em sistemas extensivos deve-se aumentar a qualidade da forragem para atingir uma maior média de conteúdo de energia metabolizável (EM). Ao alcançar níveis elevados de EM na forragem, o requerimento de alimento pelo animal é diminuído, possibilitando uma produção equivalente por hectare com menor consumo e menores índices de emissão de metano na atmosfera (WELLS, 2001).

\subsection{Pastagem e suplementação de concentrado}

Na revisão realizada por Goeset al. (2004) comentam que o fornecimento exclusivo da pastagem como fonte de proteína e energia para bovinos, seus desempenhos podem 
não corresponder ao objetivo da produção animal atualmente. Assim, a suplementação pode auxiliar na melhoria do desempenho, porém seus ganhos podem ser positivos ou negativos, dependendo de outros fatores como a qualidade e tipo de suplementação que podem ser alterados pelos seus ingredientes com efeito associativo. Também, os autores afirmam que a suplementação adequada pode auxiliar o produtor em melhorias na resposta do animal, assim como a diminuição do custo e na produção de metano no sistema.

Segundo Berndt (2010) à medida que a tecnologia é empregada em um sistema para que haja o melhor desempenho do animal, indiretamente agrega-se valor ao produto, quando valorizado o conceito ambiental. Ainda o autor afirma que quando introduzidos aditivos nutricionais, adubação de pastagens, melhoramento genético entre outras atividades haverá um balanço na produção de gases de efeito estufa, para a geração carne. Beleosoff (2013) afirma que a reduções na produção de metano, por ruminantes alimentados por forrageiras, ocorrem quando há um equilíbrio entre os nutrientes disponibilizados pela pastagem e os nutrientes aproveitados pelos microrganismos ruminais.

\subsection{Recuperação e pastagens intensificadas}

Além das práticas de suplementação de bovinos, o manejo e conservação adequada do solo e das pastagens é uma alternativa viável para os produtores como a utilização da adubação nitrogenada, em que há o aumento da produção de massa por hectare, além da melhora na composição bromatológica das forragens disponíveis para os animais. Segundo Brâncio et al. (2003) ao avaliarem o ganho de peso de bovinos em pastagem de três cultivares de capim Panicum sob sistema rotacionado em diferentes períodos do ano, observaram que pastagens com capim Tanzânia adubadas com $100 \mathrm{~kg}$ $\mathrm{N} /$ ha proporcionaram maiores ganhos de peso por animal e por hectare. Já para pastagens com capim Massai (50 kg N/ha), apresentaram os menores resultados durante a estiagem. Porém, devido sua maior capacidade de suporte, a pastagem de capim Massai, obteve maiores resultados quando comparado ao capim Mombaça e Tanzânia, no período chuvoso. Para o capim Mombaça os resultados de ganho de peso por hectare foram os menores observados devido sua baixa capacidade de suporte. 
Devido à grande quantidade de áreas degradadas no Brasil, provenientes do manejo inadequado das pastagens, muitos produtores deixam de exercer a atividade ou mesmo aumentam suas áreas por meio do desmatamento de florestas, apesar das leis ambientais do país em regiões onde não há muita fiscalização, ainda encontra-se tal atividade contribuindo para o aumento de carbono na atmosfera, pois na ausência da vegetação não haverá a fixação de carbono no solo.

Yokoyama et al. (1999) avaliaram o desempenho animal e a viabilidade econômica da recuperação de pastagens degradadas utilizando consórcio de culturas graníferas com o arroz e milho, utilizando o sistema Barreirão e o sistema convencional da região do Mato Grosso do Sul. Tais autores observaram que a recuperação de pastagens, é economicamente lucrativa, apesar do sistema Barreirão apresentar uma vantagem ao sistema convencional, uma vez que a produção do grão custeia parte do gasto na formação da pastagem. Além disto, comprovam também que pastagens degradadas são economicamente inviáveis, pois permite uma lotação animal inferior e menor ganho de peso animal. Os melhores índices econômicos encontrados pelos autores foram quando a recuperação da pastagem foi realizada pelo sistema Barreirão utilizando o consórcio com o milho. Já quando observado o custeio médio de produção de uma arroba de carcaça bovina, a recuperação da pastagem, independente do modelo utilizado, permite uma margem de renda líquida superior.

A sazonalidade na produção de forragens pode ser contornada com a utilização de métodos como a irrigação de pastagens. O uso de pastagens irrigadas com pivô central obtém resultados expressivos economicamente e em ternos de ganho de peso animal. Porém deve-se ater que a técnica pode ser utilizada em qualquer região do país, tendo algumas precauções, pois sem conhecimentos básicos, pode tornar inviável economicamente (ANDRADE, 2000).

Segundo a Embrapa (2007) a recuperação de pastagens otimiza o aproveitamento das áreas, renova as propriedades químico-físicas do solo e também favorece o ambiente, promovendo a sustentabilidade da agropecuária, reduzindo o custo para 0 produtor e agregando valor a atividade, além de preservar o meio ambiente e possibilitar emprego de sistemas conservacionista como o sistema plantio direto e a integração lavoura-pecuária. 
Beleosoff (2013) em avaliação de produção de gases totais e de metano em pastagens de Tanzânia, afirma que quando a cultura apresenta seu maior acúmulo de massa de forragem total, produz maiores quantidades de gases totais e de metano. Inversamente, observou que quando o capim atinge sua melhor condição bromatológica, ou seja, menor fibrosidade, essa emissão torna-se menor. Assim, também se conclui que em sistemas que utilizam duas espécies animais para pastejo, bovinos e ovinos, diminui a taxa de produção de metano no segundo ciclo da rotação, devido ao melhor aproveitamento da forragem pelos animais, pois possuía um menor teor de fibra.

\subsection{Confinamento}

Devido à cultura brasileira na produção de bovinos, muitos produtores ainda utilizam como forma de alimentação as pastagens nos períodos das águas e em períodos de seca adotam a utilização de confinamento. Esta prática tem como base a utilização de dietas de altos níveis de grãos e volumosos ricos em fibras de baixo custo como o bagaço de cana-de-açúcar, para a estimulação do desenvolvimento dos microrganismos do rúmen. Missio et al. (2009) avaliaram o desempenho e a viabilidade econômica de bovinos em confinamento com dietas contendo 22, 40, 59 ou 79\% de concentrado, tendo como fonte de fibra silagem de milho, observaram que a conversão alimentar diminuiu conforme houve o aumento de concentrado na dieta, porém o ganho de peso médio diário ocorreu o processo inverso, tendo para cada $1 \%$ de concentrado a mais entre as dietas houve um ganho de $6,50 \mathrm{~g}$, tais fatos, os autores correlacionam com a maior densidade de energia das dietas com maiores proporções de concentrado. Assim, concluem que com o aumento dos níveis de concentrado nas dietas à base de silagem de milho melhoram o desempenho animal, porém diminuem a lucratividade da terminação de tourinhos devido ao aumento no custo do concentrado.

Em experimento, a mensuração na produção de metano representou somente 1,9 a 2,2\% em confinamento com dietas de alto concentrado e aproximadamente 8,2\%em pastagem, confirmando a sugestão de que a produção de metano em confinamento é muito menor comparado ao sistema em pasto (BRANINE e JOHNSON, 1990). O fornecimento de alimento concentrado para ruminantes melhora o aproveitamento de nutrientes pela alta digestibilidade e rápida fermentação no rúmen, permitindo maior 
eficiência e menor produção de metano. Em confinamentos, a utilização de altos níveis de alimento concentrado, permite a redução de $2 \%$ da emissão de gases contribuintes para 0 efeito estufa, principalmente pela redução da produção de metano entérico, refletido pelo menor tempo do animal no sistema e menor produção de dejetos quando comparado ao sistema em pasto (BEAUCHEMIN, 2011).

\section{CONSIDERAÇÕES FINAIS}

O sistema de produção de bovinos de corte em pasto produz maior quantidade de metano, devido longos períodos de permanência do animal no sistema. Sem que haja manejo adequado, as forragens tornam-se de baixo valor nutritivo com altas cargas fibrosas auxiliando no processo de produção do metano em ruminantes. Assim, a adoção de métodos como a suplementação de animais em pasto, recuperação de pastagens degradadas, uso de irrigação e adubação. Ainda podem ser utilizados sistemas que auxiliam a fixação de carbono atmosférico no solo, como sistemas plantio direto, integração lavoura-pecuária, integração lavoura-pecuária-floresta.

O confinamento, por ser um sistema mais intensivo produz menor emissão de gás metano, considerando o tempo de abate (animais jovens). Pois, suas dietas, baseadas em altos níveis de concentrado permitem melhor aproveitamento dos nutrientes gerando menor produção de gás metano.

Há necessidade de maiores estudos no Brasil sobre a capacidade de produção de gás metano provinda da pecuária. Medidas conservacionistas devem ser priorizadas por pesquisadores, técnicos, profissionais e colocadas em práticas para manutenção e conservação do ambiente.

\section{REFERÊNCIAS}

ANDRADE, C.M.S. Produção de bovinos em pastagem irrigada. Viçosa, MG. Ed. UFV, 2000. Disponível em: <www.ufv.br>. Acesso em: 4 ago. 2013.

ASCHENBACH, J.R. et al. Ruminant nutrition symposium: role of fermentation acid absorption in the regulation of ruminal pH. Journal of Animal Science, v.89, p.10921107, 2011. 
BANNINK, A. et al. Modelling the implications of feeding strategy on rumen fermentation and functioning of the rumen wall. Animal Feed Science and Technology, n.143, p.3-26, 2008.

BEAUCHEMIN, K.A. Mitigation of greenhouse gas emissions from beef production inwestern Canada - Evaluation using farm-based life cycle assessment. Animal Feed Science and Technology, v.166-167, p.663-677, 2011.

BEAUCHEMIN, K.A., et al. Nutritional management for enteric methane abatement: a review. Australian Journal of Experimental Agriculture, v.48, p. 21-27, 2008.

BELEOSOFF, B.S. Potencial de produção de gases totais e metano in vitro de pastagens de Panicum maximum Jacq. cv. Tanzânia submetida a diferentes manejos de pastejo. 2013. 145f. Tese (Doutorado em Ciências Animais) - Faculdade de Agronomia e Medicina Veterinária, Universidade de Brasília, Brasília, 2013.

BERNDT, A. Impacto da pecuária de corte brasileira sobre os gases do efeito estufa. In:Simpósio de produção de gado de corte, 7., 2010, Viçosa. Anais... Viçosa, 2010. p.123148.

BRÂNCIO, P.A. et al. Avaliação de Três Cultivares de Panicum maximum Jacq. sob pastejo: composição da dieta, consumo de matéria seca e ganho de peso animal. Revista Brasileira de Zootecnia, Viçosa, v.32, n.5, p.1037-1044, 2003.

BRANINE, M.E.; JOHNSON, D.E. Level of intake effects on ruminant methane loss across a wide range of diets. Journal of Animal Science, v.68, p. 509-522, 1990.

CABRAL, L.S. et al. Suplementação de bovinos de corte mantidos em pastagem de Panicum maximum cv. Tanzânia-1 no período das águas. Revista Brasileira de Saúde e Produção Animal, Salvador, v.9, n.2, p. 293-302, 2008.

CARDOSO, A.S. Avaliação das emissões de gases de efeito estufa em diferentes cenários de intensificação de uso das pastagens no Brasil central. 2012. 84f. Dissertação (Mestrado em Agronomia, Ciência do Solo) - Instituto de Agronomia, Departamento de Solos, Universidade Federal Rural do Rio de Janeiro, Seropédica, 2012.

COTTON, W.R.; PIELKE, R.A. Human impacts on weather and climate. Cambridge: Cambridge University Press, p.288. 1995.

EMBRAPA -EMPRESA BRASILEIRA DE PESQUISA AGROPECUÁRIA.Recuperação de áreas degradadas. Brasília, 2012. Boletim técnico.

EMBRAPA MILHO E SORGO - Empresa Brasileira de Pesquisa Agropecuária. Integração lavoura pecuária. Sete Lagoas - Minas Gerais, 2007. Circular técnico 93.

FIGUEIREDO, D.M. et al. Análise econômica de quatro estratégias de suplementação para recria e engorda de bovinos em sistema pasto-suplemento. Revista Brasileira de Zootecnia. Viçosa, v.36, n.5, p.1443-1453, 2007. 
FINLAY, B.J.; FENCHEL, T. Hydrogenosomes in some anaerobicprotozoa resembling mitochondria. FEMS Microbiology Letters, v.65, p.311-314, 1989.

GOES, R.H.T.B. et al. Efeito associativo na suplementação de bovinos a pasto. Revisão. Arquivos de Ciências Veterinária e Zoologia, Umuarama, v.7, n.2, p. 163-169, 2004.

IBGE - Instituto Brasileiro de Geografia e Estatística. Indicadores IBGE - Estatística de Produção Pecuária. Disponível em: <WWW.ibge.gov.br>. Acesso em: 29 ago. 2013.

LECHARTIER, C.; PEYRAUD, J.L. The effects of forage proportion and rapidly degradable dry matter from concentrate on ruminal digestion in dairy cows fed corn silage-based diets with fixed neutral detergent fiber and starch contents. Journal of Dairy Science. v.93, p.666-681, 2010.

LIMA, M.A. Agropecuária brasileira e as mudanças climáticas globais: caracterização do problema, oportunidades e desafios. Cadernos de Ciência \& Tecnologia, Brasília, v.19, p. 451-472, 2002.

MACKIE, R.I.; GILCHRIST, F.M. Changes in lactate-producing and lactate-utilizing bacteria in relation to $\mathrm{pH}$ in the rumen of sheep during stepwise adaptation to a highconcentrate diet. Applied and Environmental Microbiology. v.38, p.422-430, 1979.

MISSIO, R.L. et al. Desempenho e avaliação econômica da terminação de tourinhos em confinamento alimentados com diferentes níveis de concentrado na dieta. Revista Brasileira de Zootecnia, Viçosa, v.38, n.7, p.1309-1316, 2009.

OECD - Organization for Economic Co-operation and Development. Estimation of Greenhouse Gas Emissions and Sinks - Expert Meeting, Background Report, Paris, 1991.

PATRA, A.K. Enteric methane mitigation technologies for ruminant livestock: a synthesis of current research and future directions. Environmental Monitoring and Assessment, v.184, p.1929-1952, 2012.

PLAIZIER, J.C. et al. Subacute ruminal acidosis in dairy cows: The physiological causes, incidence and consequences. The Veterinary Journal. v.176, p.21-31, 2008.

POULSEN, M. et al. The effect of pectin, corn and wheat starch, inulin and $\mathrm{pH}$ on in vitro production of methane, short chain fatty acids and on the microbial community composition in rumen fluid. Anaerobe, v.18, p.83-90, 2012.

SALEEM, F. et al. The bovine ruminal fluid metabolome. Metabolomics, v.9, p.360-378, 2013.

SANTOS, M.E.R. et al. Produção de bovinos em pastagens de capim-braquiária diferidas. Revista Brasileira de Zootecnia. Viçosa, v.38, n.4, p.635-642, 2009. 
USEPA - United States Environmental Protection Agency.Evaluation ruminant livestock efficiency projects and programs: peer review draft. Washington: United States Environmental Protection Agency, 48p. 2000.

WELLS, C., 2001. Total energy indicators of agricultural sustainability: dairy farming case study. Technical Paper 2001/3, Ministry of Agriculture and Forestry, Wellington, New Zealand.

YOKOYAMA, L.P. et al. Avaliação econômica de técnicas de recuperação de pastagens. Pesquisa Agropecuária Brasileira, Brasília, v.34, n.8, p.1335-1345, 1999. 